\title{
Corrigendum
}

\section{Corrigendum to "Evaluation of Urban Environmental and Economic Coordination Based on Discrete Mathematical Model"}

\author{
Chenbin Dou, ${ }^{1}$ Lan Zheng, ${ }^{1}$ and Mohammad Shabaz ${ }^{2}$ \\ ${ }^{1}$ School of Economics, Hefei University of Technology, Hefei 230601, China \\ ${ }^{2}$ Arba Minch University, Arba Minch, Ethiopia \\ Correspondence should be addressed to Lan Zheng; hfzhengl@163.com \\ Received 16 July 2021; Accepted 16 July 2021; Published 30 August 2021 \\ Copyright (C) 2021 Chenbin Dou et al. This is an open access article distributed under the Creative Commons Attribution License, \\ which permits unrestricted use, distribution, and reproduction in any medium, provided the original work is properly cited.
}

In the article titled "Evaluation of Urban Environmental and Economic Coordination Based on Discrete Mathematical Model" [1], the author Wenjuan Wang requested to remove his name from the author's list as he did not agree to be listed as an author. The remaining authors did not respond to our request to clarify this concern, and the corrected author list is shown above.

\section{Conflicts of Interest}

The authors declare that they have no conflicts of interest.

\section{References}

[1] C. Dou, L. Zheng, W. Wang, and M. Shabaz, "Evaluation of urban environmental and economic coordination based on discrete mathematical model," Mathematical Problems in Engineering, vol. 2021, Article ID 1566538, 11 pages, 2021. 